continue to work and develop relationships with their staffs to ensure that family medicine is an engaged participant in discussions regarding NIH. You can help by keeping an eye open for e-mails asking for your assistance and responding to these legislative alerts by calling your local Representative's and Senators' offices. There really is power to your voice and ideas; all you have to do is take the time to share them.

Terrence E. Steyer, MD Medical University of South Carolina Chair, STFM Legislative Affairs Committee

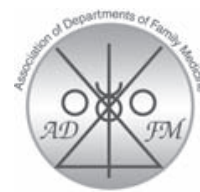

From the Association of Departments of Family Medicine

Ann Fam Med 2007;5:88-89. DOI: 10.1370/afm.671.

\section{INTELLIGENT DESIGN OR EVOLUTION? INNOVATION IN FAMILY MEDICINE RESIDENCIES}

Family Medicine Residency programs must innovate rapidly to attract applicants, compete for patients, deliver quality, and ensure that all graduates can deliver New Model care. However, powerful forces inhibit innovation precisely at a time when it should accelerate. This is the "innovator's dilemma": investment in an existing product makes fundamental change very difficult. ${ }^{1}$

From a national perspective, we must choose between alternative paths as we seek to recreate residency training: prescriptive, incremental change with predetermined outcomes vs unplanned, disorganized experiments with both failures and successes. In other words, we must choose between "intelligent design" and "evolution."

The choice is not simply between these 2 extremes; there are many points on the spectrum. However, ADFM believes we should move much farther toward "evolution" than we have to date. Failure risks extinction of the discipline of family medicine.

\section{Intelligent Design}

Careful, planned, incremental change in residencies is commendable. The Accreditation Council for Graduate Medical Education and its Residency Review Committees (RRCs), including the RRC-FM, exist "to improve health care by assessing and advancing the quality of resident physicians' education through accreditation." 2 Unstated is the premise that accreditation is intended to protect the public by enforcing minimum standards for residency programs. The RRC requirements are the organizational equivalent of DNA, the "genetic code" describing minimal structure and function for life of residencies. Accreditation follows change; it does not lead it.

The "family" of family medicine has taken important steps toward planned, incremental change in practice and training. The New Model of family medicine was developed after extensive research and widespread input ${ }_{i}$ TransforMED is helping 36 family practices implement the New Model. ${ }^{3}$ Keying off TransforMED, the ABFM, AFMRD, and AAFP have launched the Preparing the Personal Physician for Practice (P4) project to help residencies innovate. ${ }^{4}$ The $\mathrm{P} 4$ "experiments" will begin in 2007 and are expected to continue for 3 years, with evaluation of the changes in training a key part of the process.

The RRC-FM has new membership and a new executive director. We are hopeful they will be more supportive of experiments than the RRC-FM has been in the past, and that $\mathrm{P} 4$ will facilitate significant innovation. However, P4 will only work with a few programs, and it is not clear yet to what degree the RRC-FM will allow $\mathrm{P} 4$ residencies to deviate from requirements.

The process will also be slow. New RRC requirements, potentially incorporating results of "successful" P4 experiments, will not emerge for years. They represent one of our discipline's last chances to adapt to changes in medical practice for years. If this is our strategy, we better be right! Unfortunately, however, this is like assuming for ourselves the role of an omniscient "designer" to precisely anticipate future environmental pressures and implant the mutations in our "residency DNA" to ensure survival of our species.

\section{Evolution}

The alternative model is evolution, which occurs when there is sufficient genetic diversity in a population that some individuals have an adaptive advantage in the face of environmental change or competitive pressure. But diversity comes at a price: more mutations mean potential for failures.

We believe this model better describes the way family medicine should encourage innovation in our residencies. The practice of family medicine is already evolving rapidly. Family physicians are serving in a plethora of communities and environments, from large to small practices, corporate to independent work, New Model to retail clinics, hospitalist practice to low overhead practices to home visiting out of the trunks of cars.

There is no longer a single definition of family medicine. Family medicine is what people who call themselves family physicians do. Stated differently, in the high pressure ecology of practice, our species is already responding to "natural selection" forces in dif- 
ferent markets. Family physicians are even acquiring "hybrid vigor" as they pursue Masters' degrees, fellowship training, CAQs, and dual certification. Demand is high for residencies that encourage such vigor via special foci and extended training. ${ }^{5}$

Of course, the dichotomy of "intelligent design" and "evolution" is not absolute. Residents must acquire a core set of knowledge, skills, and attitudes to become family physicians. However, ADFM believes that we should not limit innovations to carefully controlled "experiments" in a few residencies around the margins of dangerously restrictive requirements. We should instead encourage residencies to find the most successful practicing family physicians in their communities, study what they do, and prepare residents to practice and adapt like these exemplary doctors. Then we should get out of the way and see what evolves.

Michael K. Magill, MD, and the Association of Departments of Family Medicine

\section{References}

1. Magill, M. Compelled to fail? The innovator's dilemma and family medicine residency programs. Ann Fam Med. 2005;3(4):375-376.

2. Accreditation Council for Graduate Medical Education (ACGME). Mission Statement. 2006. Available at: http://www.acgme.org/ acWebsite/about/ab_mission.asp. Accessed: 28 October 2006.

3. TransforMED. TransforMED homepage. 2006. Available at: http:// www.transformed.com/. Accessed: 28 October 2006.

4. P4: Preparing the Personal Physician for Practice. Available from: http://www.transformed.com/p4.cfm. 2006. Accessed: 28 October 2006.

5. Lebensohn P, Campos-Outcalt D, Senf J, Pugno PA. Experience with an optional four-year residency: the University of Arizona Family Medicine Residency. Fam Med. In press.

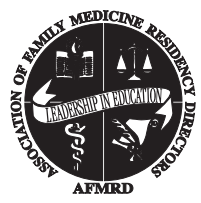

From the Association of Family Medicine Residency Directors

Ann Fam Med 2007;5:89-90. DOI: 10.1370/afm.672.

\section{EXPERIMENTATION AND INNOVATION IN FAMILY MEDICINE RESIDENCY EDUCATION: THE TIME IS NOW}

By this time, most of you have heard or read about the joint initiative between the American Board of Family Medicine and the Association of Family Medicine Residency Directors called "Preparing the Personal Physician for Practice" or the P4 Initiative. As stated in the recent Call for Proposals, "The purpose of P4 is to learn how to improve the graduate medical educa- tion of family physicians such that they are prepared to be outstanding personal physicians, working in new models of practice. The innovations tested by $\mathrm{P} 4$ residencies are expected to inspire substantial changes in the content, structure and location of training family physicians and guide future revisions in accreditation and certification requirements."

From the beginning, it was felt that the P4 Initiative would succeed or fail based on the creativity and tenacity of the folks in the trenches, ie, the residency program directors and their faculty. Therefore, prior to this year's Program Director Workshop (PDW), input was solicited from directors on the current status of residency education. The magnitude of the response (over 200 directors offered input) and the thoughtfulness of the comments demonstrated to me a significant interest in this project and a readiness for change in our graduate medical education system. Following is a synopsis of the responses received from the directors, combined with opinions expressed during the discussion forum, which was held at the 2006 PDW. These comments capture the full range of ideas expressed by the directors and though not meant to be a formal analysis of the responses, I think the comments do offer insight into our directors' thoughts and desires for the future.

In response to what important aspects of residency education need to change in the future, we received comments around the themes of decreased regulation, more curricular flexibility, more practical learning in "real-world" settings, guidance on how to adopt new technology, help in identifying new funding sources, help in developing a viable financial model for practices, and better ways to assess and assure the competency of our graduates.

In response to what important aspects of residency education need to be preserved, we received comments relating to continuity of care, breadth of training, intellectual curiosity, the personal, continuous doctor-patient relationship and the core, universal training that all residents receive, so there's consistency across the spectrum of what all family physicians can $\mathrm{do}_{\text {; }}$ ie, "training can't become totally variable."

When asked to fast forward 5 years, after the residency experiments are completed, what must we know that we currently don't, we received comments relating to how we could use more technology to improve quality and outcomes, what teaching methods are actually effective, what educational outcome measures are meaningful, how to better assess and assure competency and that the New Model of Practice is financially viable and relevant. It was clear from the comments that we need to better understand what experiences during residency are most effective in training knowledgeable and skilled family physicians. 